\title{
Desenvolvimento Humano, Convenções Internacionais e a Concretização de Direitos: O Impacto dos Compromissos Internacionais na Instituição das Políticas Públicas Brasileiras
}

\author{
Paulo Henrique Martins \\ Mestrando em Direito pelo Centro Universitário de \\ Maringá - Unicesumar. paulohenriquemartins.edu@ \\ outlook.com
}

\section{Dirceu Pereira Siqueira}

Professor do Programa de Mestrado do Centro Universitário de Maringá - Unicesumar. dpsiqueira@uol.com.br

\section{Resumo}

0 tema desenvolvimento humano é tratado no presente ensaio como sendo o compromisso brasileiro ante a comunidade internacional, para realização dos direitos humanos, implemento dos direitos de solidariedade social. Objetiva-se comprovar que há no Brasil um compromisso para a promoção do desenvolvimento humano, principalmente em decorrência da internacionalização dos direitos humanos. Utilizar-se-á de metodologia baseada em pesquisa qualitativa, tecida com base doutrinária (nacional e internacional) e jurisprudencial, abordando-se o tema pelo método hipotético-dedutivo, de cunho descritivo e analítico. Buscar-se-á provar, após abordagem da evolução dos direitos humanos e os principais tratados internacionais nos contextos global e regional, que o direito ao desenvolvimento humano possui vínculos inquestionáveis com a paz, segurança e estabilidade sociais, as quais serão efetivadas com a superação da pobreza e exclusão social. Algumas conclusões foram apresentadas: primeiro, no Brasil algumas políticas públicas que visam ao desenvolvimento humano já são praticadas, como o sistema da seguridade social (artigo 194 da CF/88); segundo, o princípio 
do desenvolvimento humano é vinculante ao Brasil, não sendo possível que o Estado retroceda, sob alegação de soberania e aplicação da legislação local, pois a internacionalização dos direitos humanos impõe o exercício de agendas políticas voltadas a comprovar o efetivo progresso do povo brasileiro.

Palavras-chave: Convenções internacionais. Desenvolvimento. Políticas públicas brasileiras.

\title{
Human Development, International Conventions and the Realization of Rights: the Impact of International Commitments on the Implementation of Brazilian Public Policies
}

\begin{abstract}
The theme of human development is treated in this essay as the Brazilian commitment to the international community, in the sense of realizing human rights, implementing so-called social solidarity rigths. The objective is to analyze the commitment in Brazil to promote human development, predominantly because of the internationalization of human rights. It will use a methodology based on qualitative research, woven on a doctrinal (national and international) basis and jurisprudential, approaching the subject by the hypothetical-deductive method, with a descriptive and analytical character. It will be tried to prove, after approaching the evolution of human rights and the main international treaties in the global and regional contexts, that the right to human development has unquestionable links with peace, security and social stability, which will be achieved by overcoming poverty and social exclusion. Some conclusions are made: first, Brazil some public policies to implement the human development are already carried out, such as the social security system (article 194 of CF / 88); second: the principle of human development is binding on Brazil, and it is not possible for the State to back down, claiming sovereignty and applying local legislation, since the internationalization of human rights requires the exercise of political agendas aimed at achieving the effective progress of the Brazilian people.
\end{abstract}

Keywords: International conventions. Development. Brazilian public policies.

Recebido em: 31/3/2017

Revisões requeridas em: 20/5/2017

Aceito em: 29/5/2017

\section{Sumário}

1 Introdução. 2 A evolução dos instrumentos normativos internacionais na defesa dos direitos humanos - breve histórico. 3 A compreensão do conceito do direito ao desenvolvimento humano nos cenários internacional e brasileiro. 4 Direito Internacional dos direitos humanos e a aplicabilidade do direito ao desenvolvimento humano no Direito brasileiro. 5 Conclusões. 6 Referências. 


\section{INTRODUÇÃO}

No presente texto pretende-se demonstrar que no Brasil há um compromisso de promover o desenvolvimento humano, seja porque signatário de vários tratados internacionais, seja pela própria internacionalização dos direitos humanos.

Tentar-se-á responder às seguintes indagações: É vinculante à realidade normativa local brasileira o princípio do desenvolvimento humano, mesmo não tendo sido ratificado para ordem interna o ato internacional da Declaração sobre o Direito ao Desenvolvimento, de 1986? O Direito Internacional dos direitos humanos obriga o Brasil a realizar políticas públicas destinadas a trazer o pleno desenvolvimento da população brasileira? Tentar responder a essa indagação é o objetivo do trabalho.

As técnicas de pesquisa utilizadas são pesquisa bibliográfica, com uso de livros, artigos, doutrina e jurisprudências nacionais e internacionais, para proporcionar uma avaliação do tema sob um novo enfoque, trazendo conclusões que visam a inovar e contribuir com o avanço dos estudos do desenvolvimento humano e os direitos humanos.

Para tanto objetiva-se analisar se há no Brasil um compromisso para a promoção do desenvolvimento humano, principalmente em decorrência da internacionalização dos direitos humanos.

Analisar-se-á no bojo do texto a evolução histórica dos instrumentos normativos internacionais de defesa dos direitos humanos, tanto na esfera global - com destaque para a Carta das Nações Unidas (1945), a Declaração Universal dos Direitos Humanos (1948), o Pacto Internacional dos Direitos Civis e Políticos e o Pacto Internacional dos Direitos Econômicos, Sociais e Culturais (ambos de 1966) - quanto na esfera regional - com destaque para a Convenção Americana de Direitos Humanos (Pacto de San José da Costa Rica). 
Propõem-se, na sequência, trazer o conceito do direito ao desenvolvimento humano nos cenários internacional e brasileiro, como corolário dos direitos voltados à solidariedade ou os denominados direitos de terceira geração.

Comparar-se-á o Direito Internacional dos direitos humanos e a questão do direito ao desenvolvimento na realidade brasileira.

Assim, a compreensão sistemática das normas que tratam da proteção da pessoa humana, principalmente com o advento da Constituição Federal de 1988, bem como pela análise dos tratados internacionais de direitos humanos já ratificados pelo Brasil, demonstram que existe um compromisso do Brasil em proteger a pessoa e promover o seu pleno desenvolvimento.

\section{A EVOLUÇÃO DOS INSTRUMENTOS NORMATIVOS INTERNACIONAIS NA DEFESA DOS DIREITOS HUMANOS - BREVE HISTÓRICO}

A partir do momento em que houve um determinado consenso internacional quanto à necessidade de se criarem condições favoráveis ao desenvolvimento das pessoas, e também, em âmbito internacional para promover os direitos humanos, principalmente após o final de Segunda Guerra Mundial, surgiram os denominados instrumentos internacionais de defesa dos direitos humanos.

Em plano global, destaca Dinah L. Shelton, são basicamente quatro os principais instrumentos sustentadores da proteção universal dos direitos humanos, quais sejam: (i) Carta das Nações Unidas (1945), a (ii) Declaração Universal dos Direitos Humanos (1948), o (iii) Pacto Internacional dos Direitos Civis e Políticos e (iv) o Pacto Internacional dos Direitos Econômicos, Sociais e Culturais (ambos de 1966) (SHELTON, 2007, p. 13-16). 
A Carta das Nações Unidas proclamou, entre outros feitos, a liberdade de discurso e de expressão, a liberdade de religião, a liberdade contra qualquer temor e a liberdade de querer e de agir, todas constituindo as quatro liberdades básicas do homem. A Carta também proclamou o direito de autodeterminação dos povos. Estes princípios foram reafirmados na Declaração das Nações Unidas de $1^{\circ}$ de janeiro de 1942 (SHELTON, 2007, p. 13-14).

A Declaração Universal dos Direitos Humanos representou um documento dotado de autonomia, pois foi o instrumento eleito pela sociedade internacional para listar os direitos mínimos do ser humano e assegurar, sobretudo, o respeito à dignidade da pessoa, bem como pretendeu extirpar a possibilidade da ocorrência de qualquer uma das atrocidades cometidas durante a Segunda Guerra Mundial (SHELTON, 2007, p. 14-15).

Sobre a importância em nível global da Declaração de Direitos Humanos, acentua Dinah Shelton que:

The first general human rights text adopted internationally was the Declaration of the Rights and Duties of Man, adopted by resolution of the Organization of American States in Bogota, at the same meeting that concluded the Charter of the Organization. [...]. The Declaration called itself "a common standard of achievement for all peoples and all nations." Eleanor Roosevelt said it might well become "the Magna Carta of all mankind.” The Declaration has become this and more, as it today represents an agreed statement of the definition of "human rights" as that term is used in the United Nations Charter. It has been reaffirmed in global and regional treaties and in the United Nations Conferences on Human Rights (Teheran, Vienna). This early agree- 
ment on the content of human rights cannot be over-emphasized. The recasting human rights policy as international law made it more difficult for states to ignore human rights claims $(2007$, p. 15$){ }^{1}$

Destarte, os 30 artigos da Declaração dos Direitos Humanos direcionam-se a duas finalidades inafastáveis, quais sejam, a preservação da dignidade humana e a imprescindibilidade de tratamento igualitário das pessoas, independentemente de sua origem, sexo, idade, cor, etc.

A Declaração da ONU reafirma os ideais de liberdade e igualdade consagrados em 1789, após a Revolução Francesa. Assim, esse documento universal reconhece que a ideia de dignidade humana é inerente ou indissociável do homem em razão do seu nascimento, isto é, basta ter nascido para ser digno como ser humano.

Isso é o contraponto ao nazismo alemão que apregoava a discriminação, por meio da eleição da raça superior, destruindo a noção de igualdade. O Estado discriminador transmutava-se em genocida, escolhendo grupos de pessoas para serem mortas: judeus, negros, ciganos, homossexuais, etc. A Declaração, portanto, buscou (e busca) impedir as diferenças, sobretudo para preservar o direito à vida.

René Cassin destaca o caráter universal da Declaração de Direitos de 1948:

\footnotetext{
1 "O primeiro texto geral dos direitos humanos internacionalmente adotado foi a Declaração dos Direitos e Deveres do Homem, adotada pela resolução da Organização dos Estados Americanos, em Bogotá, na mesma reunião que concluiu a Carta da Organização. [...]. A própria Declaração foi chamada de "o ideal comum a ser atingido por todos os povos e todas as nações.” Eleanor Roosevelt disse que esta poderia bem tornar-se 'a Carta Magna de toda a humanidade.' A Declaração se tornou isso e muito mais, uma vez que hoje representa uma declaração acordada quanto à definição de 'direitos humanos' bem como essa expressão é utilizada na Carta das Nações Unidas. Foi reafirmada [a expressão direitos humanos] em tratados globais e regionais e nas conferências das Nações Unidas sobre os Direitos Humanos (Teerã, Viena). Este acordo sobre o conteúdo dos direitos humanos não pode ser mais enfatizado. A política de reformulação dos direitos humanos do direito internacional tornou mais difícil para os estados ignorar as reivindicações de direitos humanos”. Tradução livre dos autores.
} 
Seja-me permitido, antes de concluir, resumir as características da Declaração, elaborada a partir de nossos debates no período de 1947 a 1948. Esta Declaração se caracteriza, primeiramente, pela sua amplitude. Compreende um conjunto de direitos e faculdades sem as quais um ser humano não pode desenvolver sua personalidade física, moral e intelectual. Sua segunda característica é a universalidade: é aplicável a todas as pessoas de todos os países, raças, religiões e sexos, seja qual for o regime político dos territórios nos quais incide. Ao finalizar os trabalhos, a Assembleia Geral, graças à minha proposição, proclamou a Declaração Universal, tendo em vista que, até então, ao longo dos trabalhos, era denominada Declaração Internacional. Ao fazê-lo, conscientemente, a comunidade internacional reconheceu que o indivíduo é membro direto da sociedade humana, na condição de sujeito direto do Direito das Gentes. Naturalmente, é cidadão do seu país, mas também é cidadão do mundo, pelo fato mesmo da proteção internacional que lhe é assegurada. Tais são as características centrais da Declaração. (...) A Declaração, adotada por unanimidade (com apenas 8 abstenções, em face de 48 votos favoráveis), teve imediatamente uma grande repercussão moral nas Nações. Os povos começaram a ter consciência de que o conjunto da comunidade humana se interessava pelo seu destino (1974, p. 397).

Segundo Flávia Piovesan, a Declaração Universal tem como finalidade o respeito à dignidade da pessoa humana. Este valor, precípuo e inerente à condição da pessoa, foi posteriormente incorporado por todos os tratados e declarações de direitos humanos que se seguiram (PIOVESAN, 2012a, p. 204).

A Declaração, destaca Daniel Sarmento, veio em resposta à ineficácia dos direitos da primeira geração que foram pautados na lógica do Estado liberal, em que o Estado deveria ser reduzido ao mínimo de ação. Essa perspectiva relacionava-se de forma próxima ao laissez-faire e a crença da "mão invisível”, ou seja, que o poder econômico equacionaria, por si só, os problemas sociais (SARMENTO, 2004, p. 29). 
Clémerson Merlin Cléve resume o fracasso do modelo liberal e o culto ao legalismo exacerbado:

O culto da lei pelo liberalismo produziu consequências. É que o culto da lei como forma e conteúdo foi, lentamente, sendo substituído pelo simples culto da lei como forma. A identificação do direito com a lei acabou dando lugar a toda uma concepção formalista da experiência jurídica, assim denominada de positivismo. A lei contém todo o direito, é expressão máxima desta concepção (1995, p. 35).

Os progressos experimentados pela humanidade com o liberalismo foram inegáveis (ex.: progresso científico e tecnológico, entre outros), mas os direitos liberais se mostraram, todavia, insuficientes para a proteção da dignidade humana, haja vista a exploração do homem e as condições degradantes de trabalho ocorridas na Revolução Industrial. ${ }^{2}$

Para Antônio M. Hespanha, citando a doutrina marxista, a liberdade privada postulada pelo ideário da burguesia pautava-se em falsa concepção, uma utopia, pois,

[a liberdade privada trazia] uma realidade imaginária - a de indivíduos senhores de suas vontades, negociando paritariamente - totalmente contraditória com a realidade efectiva, que era antes a de indivíduos condicionadas por constrangimentos econômicos, sociais e negociando em posições desequilibradas (1997, p. 221).

2 Émile Zola, em sua obra Germinal, retrata bem a precariedade das relações dos trabalhadores, quando retrata o trabalho abusivo a que eram submetidos os trabalhadores nas minas, em que o trabalho era prestado em condições insalubres, sujeito a incêndios, explosões, intoxicação por gases, inundações, desmoronamentos. Os empregados laboravam por baixos salários e estavam sujeitos a várias horas de trabalho, ou seja, muito além de oito horas diárias. Relata o autor que nas minas ocorriam muitos acidentes do trabalho, além de serem os empregados acometidos por várias doenças decorrentes dos gases, da poeira, de estarem em local encharcado. Os empregados trabalhavam direta ou indiretamente nas minas, com praticamente toda a sua família, o pai, a mulher, os filhos, os filhos dos filhos, etc. Os contratos de trabalho eram verbais e vitalícios ou então se estabelecia condição resolutiva, qual seja, o trabalhador era empregado da mina enquanto este pudesse prestar serviços, implicando verdadeira servidão. Havia, inclusive, a prática de "compra e venda" de empregados, que eram vendidos com seus filhos. Os trabalhadores ficavam sujeitos a multas, que absorviam seu salário. Essa situação perdurou até que foram elaborados os decretos parlamentares de 1774 e 1779, quando foram suprimidas essas questões nas minas escocesas (ZOLA, 2006). 
Postos em xeque o sistema burguês e a hegemonia burguesa, foi sendo consolidada a ideia de que, para o efetivo desfrute dos direitos individuais, era necessário que fossem garantidas as condições mínimas de existência para cada ser humano. Daniel Sarmento reconhece que a mudança do sistema liberal e a inauguração do "estado do bem-estar social” ocorreu na virada do século 20, com a crise do capitalismo, no interstício das duas guerras mundiais (SARMENTO, 2004, p. 33).

Com essa mudança de eixo axiológico e do próprio papel do Estado para com os indivíduos, iniciou-se a preocupação quanto à efetiva positivação dos direitos sociais e econômicos no bojo das Constituições Nacionais, fato que escancarou a realidade de que havia muita desigualdade social (que foi sendo intensificada com o passar dos anos) cuja atuação do livre-mercado jamais seria apta a acabar. Dessa forma, se o Estado não criasse mecanismos de proteção do mais fraco em relação ao mais forte, os ideais de liberdade, igualdade e solidariedade, pregados na Declaração de Direitos, seriam frustrados (SARMENTO, 2004, p. 24).

O mote a ser seguido pelo Estado era assegurar as condições materiais mínimas à pessoa, tudo para que as liberdades públicas consagradas na primeira geração de direitos fossem efetivamente desfrutadas pelos seus titulares. $\mathrm{O}$ estabelecimento de condições materiais (prestacionais) pelo Estado inaugurou, portanto, a segunda geração de direitos (SARMENTO, 2004, p. 35).

Nesse contexto, Flávia Piovesan destaca que o processo de universalização dos direitos humanos, em si, trouxe a necessidade de os Estados buscarem mecanismos efetivos para efetivação desses direitos, posto que, sob o enfoque essencialmente legalista, a Declaração Universal não goza de força jurídica vinculante aos Estados signatários (PIOVESAN, 2012a, p. 225). 
Diante desse problema de ordem prática (e de execução), em 1948 instaurou-se grande discussão sobre qual seria a forma de instituição eficaz para o reconhecimento e observância dos direitos previstos na aludida Declaração. Nessa discussão ganhou a corrente que sugeriu a “judicialização” da Declaração, na forma de tratado internacional (2012a, p. 225-226).

A “judicialização”, que fora iniciada em 1949 e concluída em 1966, resultou na elaboração de dois tratados internacionais distintos: o primeiro, denominado de "Pacto Internacional dos Direitos Civis e Políticos", e o segundo de "Pacto Internacionais dos Direitos Econômicos, Sociais e Culturais”, que passaram a incorporar os direitos constantes da Declaração Universal (PIOVESAN, 2012a, p. 225-226).

O Pacto Internacional dos Direitos Civis e Políticos destacou-se por apresentar uma imposição aos Estados-partes de assegurar os direitos previstos no Pacto, seja trazendo rol de obrigações estatais positivas (ex.: criar um aparato legal de proteção) e também negativas (ex.: não torturar). No Brasil, a ratificação e incorporação do Pacto Internacional de Direitos Civis e Políticos deu-se por meio do Decreto 591, de 6 de julho de 1992 (BRASIL, 1992a).

\section{Para Piovesan:}

O Pacto dos Direitos Civis e Políticos proclama, em seus primeiros artigos, o dever dos Estados-partes de assegurar os direitos nele elencados a todos os indivíduos que estejam sob a sua jurisdição, adotando medidas necessárias para esse fim. A obrigação do Estado inclui também o dever de proteger os indivíduos contra a violação de seus direitos perpetrada por entes privados. Isto é, cabe ao Estado-parte estabelecer um sistema legal capaz de responder com eficácia às violações de direitos civis e políticos (2012a, p. 229). 
O Pacto Internacional de Direitos Econômicos, Sociais e Culturais enuncia um grande rol de direitos, que inclui o direito ao trabalho e à justa remuneração, o direito a formar e associar-se a sindicatos, o direito a um nível de vida adequado, o direito à moradia, à educação, à previdência social, à saúde e o direito à participação na vida cultural da comunidade (PIOVESAN, 2012a, p. 242).

No Brasil, o processo de ratificação e incorporação do Pacto Internacional de Direitos Econômicos, Sociais e Culturais se deu com a publicação, em 6 de julho de 1992, do Decreto n. 592 do Congresso Nacional, quando o Brasil ratificou, na íntegra, o Pacto Internacional de Direitos Civis e Políticos da ONU (BRASIL, 1992b).

Enquanto o Pacto de Direitos Civis direciona-se aos indivíduos, o Pacto de Direitos Econômicos, Sociais e Culturais é voltado para os Estados, uma vez que, segundo Piovesan (2012a, p. 243), “enquanto o primeiro Pacto determina que 'todos têm direito a [...]' ou 'ninguém poderá [...]', o segundo Pacto usa a fórmula 'os Estados-parte reconhecem o direito de cada um a [...]"”.

Uma outra diferença destacada é que enquanto os direitos civis e políticos devem ter aplicabilidade imediata, os direitos sociais e econômicos apresentam aplicabilidade progressiva (daí dependerem das ações afirmativas dos Estados, com a maximização de recursos nesse contexto) (PIOVESAN, 2012a, p. 243).

Essa aplicação progressista demanda o reconhecimento da cláusula de proibição ao retrocesso, bem como a assunção do compromisso do Brasil em pôr em prática as políticas públicas voltadas a atender esses direitos, cabendo ao Estado provar que não retrocedeu, perante os demais Estados e organizações internacionais (2012a, p. 243). 
Esse dever do Estado-membro de prestar contas perante a comunidade internacional, em relação ao progresso e desenvolvimento das políticas públicas, vem sendo realizado por meio dos relatórios (que são exigidos pelo Pacto Internacional dos Direitos Civis e Políticos), o que, segundo Audrey Chapman, nem sempre possuem a confiabilidade necessária, diante da possibilidade de serem fraudados:

Um monitoramento efetivo do Pacto Internacional de Direitos Econômicos, Sociais e Culturais não está sendo realizado e retificar essa situação requer uma mudança no paradigma de avaliação concernente ao cumprimento das disposições do Pacto. [...] Uma "realização progressiva", o paradigma corrente usado para avaliar a atuação dos Estados-partes, torna os direitos econômicos, sociais e culturais direitos muito difíceis de monitorar. Um paradigma que tomasse a "perspectiva das violações" constitui uma alternativa mais viável. Para facilitar o monitoramento no tocante ao Pacto, sugere-se uma classificação das violações em três categoriais: “1. Violações resultantes de ações, políticas e legislações governamentais; 2. Violações relacionadas com padrões de discriminação; e 3. Violações relacionadas com o fracasso estatal em responder às suas obrigações mínimas tocantes aos direitos enumerados (CHAPMAN, 1995, p. 313-314).

No contexto regional, em paralelo aos sistemas globais, atendendo-se às necessidades locais (e contextos culturais específicos), foram surgindo, para Heyns e Frans Viljoen (1999, p. 423), os sistemas regionais de proteção dos direitos humanos:

Enquanto o sistema global de proteção dos direitos humanos geralmente sofre com a ausência de uma capacidade sancionatória que têm os sistemas nacionais, os sistemas regionais de proteção dos direitos humanos apresentam vantagens comparativamente ao sistema da ONU: podem refletir com maior autenticidade as peculiaridades e os valores históricos dos povos de uma determinada região, resultando em uma aceitação mais espontânea e, devido à aproximação geográfica dos Estados envolvidos, os sistemas regionais têm a potencialidade de exercer 
fortes pressões em face de Estados vizinhos, em casos de violações. [...] Um efetivo sistema regional pode consequentemente, complementar o sistema global em diversas formas (apud PIOVESAN, 2012a, p. 318).

É consolidada, dessa forma, a convivência de um sistema global - integrado pelos instrumentos das Nações Unidas, como a Declaração Universal de Direitos Humanos, o Pacto Internacional dos Direitos Civis e Políticos, o Pacto Internacional dos Direitos Econômicos, Sociais e Culturais, já mencionados anteriormente - com os instrumentos dos sistemas regionais de proteção, entre eles (pela proximidade e corte geográfico deste ensaio) destacando-se o sistema interamericano. ${ }^{3}$

A Convenção Americana de Direitos Humanos, ou também conhecida como Pacto de San José da Costa Rica, foi assinada na Costa Rica em 1969, entrando em vigor em 1978. Conforme Flávia Piovesan, “apenas Estados-membros da Organização dos Estados Americanos têm o direito de aderir à Convenção Americana, que, até maio de 2011, contava com 25 Estados-partes” (2012a, p. 324).

3 Há consenso de que são basicamente três sistemas regionais principais de direitos humanos, quais sejam: o europeu, o interamericano e o africano, conforme destaca Henry Steiner. Acrescenta o autor que “[...] tanto o Conselho Europeu como a Organização dos Estados Americanos têm estabelecido programas de direitos humanos para as respectivas regiões que, em importante aspectos, são mais efetivos que os adotados pelas Nações Unidas. Em 1981, os Estados africanos introduziram um sistema regional de direitos humanos quando a Organização da Unidade Africana adotou a Carta Africana de Direitos Humanos e dos Povos (Regional arrangements). Sobre o incipiente sistema árabe, acrescente-se que, em 1945, foi criada a Liga dos Estados Árabes, e em 1994 os Estados da Liga adotaram a Carta Árabe dos Direitos Humanos, que reflete a islâmica lei da sharia e outras tradições religiosas. Até outubro de $2009 \mathrm{dez}$ Estados haviam ratificado a Carta Árabe de Direitos Humanos. Já no tocante ao sistema asiático, em 1997 uma Carta Asiática dos Direitos Humanos foi concluída sob a forma de uma declaração feita por expressivas ONGs. A Carta endossa os princípios da universalidade e da indivisibilidade dos direitos humanos, bem como os direitos ao desenvolvimento sustentável, à democracia e à paz, com a crítica à visão autoritária dos asian values (STEINER, 2000). 
O Brasil promulgou a Convenção Americana por meio do Decreto n. 678 , de 6 de novembro de 1992, data que entrou em vigor a aludida Convenção. O texto ratificado possui ressalvas (ou "declarações interpretativas") quanto aos artigos 43 e 48, alínea $d$, da Convenção, uma vez que o Brasil convencionou a não inclusão do direito automático de visitas e inspeções in loco a serem realizados por meio da Comissão Interamericana de Direitos Humanos em território nacional, que dependerão de autorização expressa do Estado brasileiro para serem realizadas (BRASIL, 1992c).

De forma concreta, a Convenção Americana de Direitos Humanos assegura um catálogo de direitos que muito se aproxima daqueles contidos no Pacto Internacional dos Direitos Civis e Políticos, destacando-se o direito à vida, a não ser submetido à escravidão, à liberdade, a um julgamento justo, à compensação em caso de erro judiciário, à privacidade, à liberdade de consciência e religião, à liberdade de pensamento e expressão, à resposta, ao nome, à nacionalidade, à liberdade de movimento e residência, de participar do governo, à igualdade perante a lei e à proteção judicial (PIOVESAN, 2012a, p. 324).

A Convenção Americana deixa de especificar de forma expressa, todavia, qualquer direito social, cultural e econômico, apenas fazendo referência que os Estados têm o compromisso de alcançar, progressivamente, a plena realização desses direitos por meio do emprego de medidas legais (legislativas) e outras que se mostrarem apropriadas, nos termos do artigo 26 da Convenção (2012a, p. 325).

Como enfatizam Thomas Buergenthal e Robert Norris:

Os Estados-partes na Convenção Americana têm a obrigação não apenas de "respeitar" esses direitos garantidos na Convenção, mas também de "assegurar" o seu livre e pleno exercício. Um governo tem, conseqüentemente, obrigações positivas e negativas relativamente à Convenção Americana. De um lado, há a obrigação de não violar direitos individuais; por exemplo, há o dever de não torturar um indivíduo 
ou de não privá-lo de um julgamento justo. Mas a obrigação do Estado vai além desse dever negativo e pode requerer adoção de medidas afirmativas necessárias e razoáveis, em determinadas circunstâncias, para assegurar o pleno exercício dos direitos garantidos na Convenção Americana. Por exemplo, o Governo de um país em que há o desaparecimento de indivíduos em larga escala está a violar o artigo $7^{\circ}$ (1) da Convenção Americana, ainda que não possa demonstrar que seus agentes sejam responsáveis por tais desaparecimentos, já que o Governo, embora capaz, falhou em adotar medidas razoáveis para proteger os indivíduos contra tal ilegalidade (1982, p. 442).

Algumas observações merecem ser feitas a respeito dos Pactos de 1966 e o sistema regional da Convenção Americana (do qual o Brasil faz parte).

Primeiro: embora haja paralelo entre os direitos de primeira e segunda gerações com (e respectivamente) os Pactos de Direitos Civis e Políticos e Direitos Econômicos, Sociais e Culturais, como sendo direitos "segmentados" (ou compartimentados em diferentes aspectos de proteção do sujeito), a corrente garantista (adotada neste ensaio) deixa clara e de forma expressa a inexistência de qualquer hierarquia entre os direitos individuais (de "primeira geração" e frequentemente relacionados ao Pacto de Direitos Civis e Políticos) e sociais (de "segunda geração” e frequentemente relacionados ao Pacto de Direitos Econômicos, Sociais e Culturais), pois ambos são manifestações dos direitos fundamentais e existem para o mesmo fim, que é proteger e promover a dignidade da pessoa humana.

A promoção dos direitos humanos, enquanto direitos sem sujeitos predeterminados (direitos da humanidade) inaugurou a "terceira geração de direitos”, com pautas de proteção expressamente voltadas ao desenvolvimento da população, ao meio ambiente, ao progresso, complementando o rol de proteção angariado com as "primeira e segunda gerações". 
Sobre o tema, são extremamente oportunas as palavras de Fábio Konder Comparato, que ressalta a interdependência e simbiose entre os direitos individuais e sociais:

[...] os direitos humanos [...] formam um conjunto uno e indivisível. A liberdade individual é ilusória, sem um mínimo de igualdade social; e a igualdade social imposta com sacríficos dos direitos civis e políticos acaba engendrando, mui rapidamente, novos privilégios econômicos e sociais (COMPARATO, 1999, p. 305).

Segundo: a ausência de hierarquia entre os direitos previstos no Pacto de Direitos Civis e Políticos e os direitos previstos no Pacto de Direitos Econômicos, Sociais e Culturais, decorre do princípio da proibição (ou vedação) ao retrocesso, segundo o qual as conquistas em sede de direitos humanos são somadas às já existentes e integram um todo uniforme. Conforme esclarece Valerio de Oliveira Mazzuoli, “[...] os Estados estão proibidos em retroceder de proteção dos direitos humanos” (2013, p. 856).

O autor segue seu raciocínio concluindo:

[...] vários tratados de direitos humanos já contêm cláusulas que dispõem que nenhuma de suas disposições "pode ser interpretada no sentido de limitar o gozo e exercício de qualquer direito ou liberdade que possam ser reconhecidos em virtude de leis de qualquer dos Estados-partes ou em virtude de Convenções em que seja parte um dos referidos Estados”, tal como faz o art. 29, alínea $b$, da Convenção Americana de Direitos Humanos de 1969 (MAZZUOLI, 2013, p. 856).

Existe, todavia, conforme destaca Daniel Sarmento, uma resistência ideológica da aplicação (imediata e efetiva) quanto aos Direitos Econômicos Sociais e Culturais, uma vez que vão demandar uma mudança da própria estrutura política em que está inserida a sociedade: 
[...] não há como ocultar o fato de que os direitos sociais ensejam maiores dificuldades para a sua afirmação concreta do que os direitos liberais. Por último lado, existe a resistência ideológica: pela sua vocação para promoção da justiça distributiva, os direitos sociais acenam para uma transformação do "status quo", e por isso mobilizam contra si os interesses de estratos privilegiados da sociedade, que não desejam mudanças. Mas há também graves obstáculos operacionais, na medida que os direitos sociais, em razão de sua natureza eminentemente prestacional, carecem de recursos públicos que são escassos (SARMENTO, 2004, p. 36).

Essa resistência ideológica frustra, inclusive, os compromissos internacionais assumidos pelos Estados quando da ratificação e assunção dos tratados internacionais de direitos humanos, o que merecerá sanção de organismos internacionais.

Terceiro: a Convenção Americana de Direitos Humanos, na condição de sistema regional de proteção da dignidade de toda pessoa, reproduziu, como referido, os principais instrumentos protetivos do Pacto dos Direitos Civis e Políticos, mas também inseriu, no bojo do Tratado, a obrigação dos Estados signatários em promover os direitos voltados à dignidade, principalmente aqueles relacionados ao desenvolvimento humano, conforme previsão do artigo 26 da Convenção. ${ }^{4}$

Sob essa perspectiva, o Brasil assumiu compromisso de realizar efetivamente os direitos humanos (ditos de terceira geração), proporcionando melhores condições de vida à população, cuidando de garantir o

4 “Artigo 26. Desenvolvimento progressivo: Os Estados-Partes comprometem-se a adotar providências, tanto no âmbito interno como mediante cooperação internacional, especialmente econômica e técnica, a fim de conseguir progressivamente a plena efetividade dos direitos que decorrem das normas econômicas, sociais e sobre educação, ciência e cultura, constantes da Carta da Organização dos Estados Americanos, reformada pelo Protocolo de Buenos Aires, na medida dos recursos disponíveis, por via legislativa ou por outros meios apropriados" (BRASIL, 1992c). 
efetivo direito ao progresso e desenvolvimento humano, tendo em vista que é signatário dos pactos internacionais de sistema global e regional de proteção dos direitos da pessoa humana.

\section{A COMPREENSÃO DO CONCEITO DO DIREITO AO DESENVOLVIMENTO HUMANO NOS CENÁRIOS INTERNACIONAL E BRASILEIRO}

A pessoa humana, independentemente de sua origem ou nacionalidade, é sujeito central de direitos na órbita dos Estados, ou seja, deve ser o sujeito participante ativo e beneficiário das vantagens experimentadas pela vida em sociedade.

A compreensão de sociedade, como o conjunto de pessoas que partilham do mesmo bem comum, impõe o reconhecimento (e a responsabilidade dos Estados) pelo desenvolvimento individual e coletivo dos serem humanos, permitindo, mediante as liberdades públicas, o pleno exercício dos direitos fundamentais, mas, sobretudo, possibilitando à parcela mais carente a real possibilidade de se desenvolver e exercer seu papel, enquanto sujeito individual, em um contexto plural.

A concepção contemporânea dos direitos humanos (que surgiu a partir da Declaração Universal de 1948 e reiterada pela Declaração de Direitos Humanos de Viena, de 1993) possui como pressupostos os processos de universalização e internacionalização desses direitos. ${ }^{5} \mathrm{~A}$ base para a sua construção deve ser o regime democrático, porque não há como falar em direitos humanos sem democracia (PIOVESAN, 2012b, p. 104).

5 Nesse sentido é a Convenção sobre a Eliminação de Todas as Formas de Discriminação Racial, a Convenção sobre a Eliminação da Discriminação contra a Mulher, a Convenção sobre os Direitos da Criança, a Convenção para a Proteção dos Direitos dos Trabalhadores Migrantes e dos Membros de suas Famílias e a Convenção sobre os Direitos das Pessoas 
Destaca Celso Lafer que o direito ao desenvolvimento, em sede dos países do Terceiro Mundo, trouxe a necessidade de estes criarem uma identidade cultural própria, uma vez que os países subdesenvolvidos estavam distantes do eixo de batalha (e de polaridade definida) que se iniciou com a guerra fria, quando, de um lado, os Estados Unidos deflagravam campanha para assegurar sobretudo os direitos civis e políticos; de outro a ex-URSS pregava a efetivação, pelo Estado, dos direitos econômicos, sociais e culturais (LAFER, 1999).

A busca pela identidade cultural aos países subdesenvolvidos representa o primeiro passo para desmascarar suas deficiências (financeiras, de políticas públicas ou da própria opção política), e que repercutem na persistência das mazelas sociais que impedem o desenvolvimento da pessoa humana. Com base na identificação das necessidades, ter-se-ão definidas as pautas prioritárias de proteção de direitos dos concidadãos.

Verifica-se claramente que a cultura e realidades locais trazem sérias distinções quanto à escolha das pautas de proteção de direitos do homem, pois, por exemplo, na realidade dos países da Europa e Estados Unidos (nações desenvolvidas ou industrializadas), os avanços dos direitos humanos ligados aos direitos sociais (ou ao próprio desenvolvimento humano) não são prioridade do sistema, e que direitos sociais só se consolidaram em aludidos países a partir do século 20, ou seja, depois do final de duas guerras mundiais, quando uma maioria de Estados decidiu traçar pautas sociais em resposta às atrocidades cometidas pelos regimes autoritários (BRITO, 1998). Assim, para os aludidos países, direitos sociais não eram tratados como prioridades elementares no Estado.

com Deficiência, que contemplam não apenas direitos civis e políticos, mas também direitos sociais, econômicos e culturais, o que vem a endossar a ideia da indivisibilidade dos direitos humanos. 
De outro lado, quando se volta para as realidades dos países subdesenvolvidos, no sentido de definir quais seriam as pautas de direitos humanos mais urgentes, os direitos sociais e os que proporcionam o desenvolvimento humano detêm posição de destaque, uma vez que a realidade cultural do povo subdesenvolvido é de ser aquele grupo de cidadãos incapazes de gozar de direitos básicos, o que gera um ciclo quase insuperável de pobreza que somente pode ser solucionado pelo Estado.

Falar em desenvolvimento também remete à ideia das condições de sustentabilidade como paradigma de vida. Ainda em 1983 a ONU criou a Comissão Mundial sobre Meio Ambiente e Desenvolvimento como organismo independente. O fruto dessa Comissão veio em 1987, quando a primeira-ministra da Noruega, Gro Harlem Brundtland, escreve o relatório “Nosso Futuro Comum”, responsável por trazer os primeiros conceitos de desenvolvimento sustentável (ORGANIZAÇÃO..., 1988, p. 46).

Aludido relatório define o desenvolvimento sustentável como “aquele que atende às necessidades do presente sem comprometer a possibilidade de as gerações futuras atenderem a suas próprias necessidades”. O atendimento a essas necessidades impõe, sobretudo, atender às demandas essenciais aos pobres, que "devem receber a máxima prioridade” e também “a noção das limitações que o estágio da tecnologia e da organização social impõe ao meio ambiente, impedindo-o de atender às necessidades presentes e futuras” (ORGANIZAÇÃO..., 1988, p. 46).

E “ao definirem os objetivos do desenvolvimento econômico e social” - prossegue o relatório - "é preciso levar em conta sua sustentabilidade em todos os países - desenvolvidos ou em desenvolvimento, com economia de mercado ou de planejamento central”. Aludido documento, contudo, adverte que "haverá muitas interpretações, mas todas elas terão características comuns e devem derivar de um consenso quanto 
ao conceito básico de desenvolvimento sustentável e quanto a uma série de estratégias necessárias para sua consecução” (ORGANIZAÇÃO..., 1988, p. 46).

Esse ápice da consecução dos esforços dos países para estabelecerem um meio-termo do binômio desenvolvimento versus meio ambiente sadio ocorreu em 1992, durante a Cúpula da Terra, no Rio de Janeiro. Sob o tema central de Desenvolvimento Sustentável, a Conferência do Rio aprovou dois tratados internacionais (a Convenção sobre Alteração Climática e a Convenção sobre Diversidade Biológica) e ainda três documentos internacionais (a Declaração do Rio sobre Meio Ambiente e Desenvolvimento, a Declaração de Princípios sobre o Manejo das Florestas e a Agenda 21). Este último documento é um plano abrangente de ação com vistas ao desenvolvimento sustentável no mundo todo até o século 21 (OLIVEIRA, 2011).

A sustentabilidade como paradigma da vida digna, em sua matriz ecológica, deve pautar-se nos seguintes pontos: (i) promoção de uma educação ambiental, reforçando e cientificando as responsabilidades individuais e coletivas diante das questões ambientais e humanas; (ii) incentivar a livre economia que tenha o objetivo de propiciar o equacionamento custos versus benefícios humanos e ambientais; (iii) propiciar a promoção humana e a melhoria da qualidade de vida em todos os seus aspectos (alimentação, educação, habitação, trabalho, saúde, etc.), eliminando a marginalização socioeconômica e promovendo a dignidade; (iv) promover a ética de sociedade sustentável, com a realização do planeta harmônico e do desenvolvimento da cidade plena e dignidade da pessoa humana (OLIVEIRA, 2011). 
Nesse contexto, a Declaração sobre o Direito ao Desenvolvimento, assinada em 1986 por 146 Estados, com um voto contrário (dos EUA) e oito abstenções, ganha extrema importância nas realidades dos países subdesenvolvidos, como uma forma de suplantar as mazelas sociais e garantir o mínimo de direitos sociais.

\section{Para Allan Rosas:}

A respeito do conteúdo do direito ao desenvolvimento, três aspectos devem ser mencionados. Em primeiro lugar, a Declaração de 1986 endossa a importância da participação [...]. Em segundo lugar, a Declaração deve ser concebida no contexto das necessidades básicas de justiça social [...]. Em terceiro lugar, a Declaração enfatiza tanto a necessidade de adoção de programas e políticas nacionais, como da cooperação internacional (1995, p. 254-255).

Nos países da América do Sul, o direito ao desenvolvimento tem tido ações ligadas a organizações da sociedade civil e de políticas públicas governamentais, sobretudo após os períodos ditatoriais e a redemocratização. De acordo com Martín Abregú, a partir das demandas das vítimas dos regimes totalitários, sobretudo na defesa de grupos particulares de mulheres, indígenas e pessoas com deficiências, alcançou-se novo grau de desenvolvimento (ABREGÚ, 2008, p. 6-41).

$\mathrm{Na}$ América Latina, justamente para romper a marginalização e exclusão social desses grupos minoritários foi criada a Cepal, ${ }^{6}$ como forma de instituição de um plano de desenvolvimento nos países periféricos do

${ }_{6}$ Comissão Econômica para América Latina e o Caribe (Cepal), criada por meio da Resolução n. 106 do Conselho Econômico e Social (Ecosoc) das Nações Unidas (ONU) em 25 de fevereiro de 1948, formada por 45 Estados-membros da América Latina e do Caribe, junto com algumas nações da América do Norte, Europa e Ásia que mantêm vínculos históricos, econômicos e culturais com a região. Ainda fazem parte da Cepal 13 membros associados (condição jurídica atribuída a alguns territórios não independentes do Caribe) (SOUZA, 1995, p. 143). 
Sul, de forma a possibilitar, inclusive, o rompimento do ranço colonizador. O ideal da Cepal era efetivar políticas públicas, principalmente ligadas à industrialização, como forma de superar o subdesenvolvimento e a pobreza (SOUZA, 1995, p. 143).

O Brasil, embora não tenha ratificado o ato internacional da Declaração sobre o Direito ao Desenvolvimento, este fato não retira, por meio da compreensão sistemática dos Tratados Internacionais já ratificados e a própria ordem interna, a obrigação jurídica de promover o desenvolvimento da pessoa humana no território nacional.

Essa obrigação jurídica é retirada do artigo $3^{\circ}$, inciso II da Constituição Federal de 1988, que traz como objetivo fundamental da República Federativa do Brasil a garantia ao desenvolvimento nacional (BRASIL, 1988). O direito ao desenvolvimento humano vai além da prestação material à pessoa, no sentido de fornecer meios materiais de subsistência, mas sim representa uma coligação de dimensões que envolvem a própria base fundante de um Estado, seus valores e objetivos centrais.

Nessa ótica, Flávia Piovesan destaca que o direito ao desenvolvimento contempla três dimensões centrais: justiça social, participação e programas e políticas nacionais de cooperação internacional (2012b, p. 104-105).

Por justiça social compreende-se o direito que toda a pessoa tem de ser respeitada na ordem internacional para a realização de todas as liberdades inerentes ao homem. Essa concepção é retirada do artigo 28 da Declaração dos Direitos Humanos, a qual estatui: "Toda pessoa tem direito a uma ordem social e internacional em que os direitos e liberdades estabelecidos na Declaração possam ser plenamente realizados” (BRASIL, 1992a).

A mencionada autora destaca que a concepção dada pela Declaração ao direito ao desenvolvimento significa 
[...] um processo econômico, social, cultural e político, com o objetivo de assegurar a constante melhoria do bem-estar da população e dos indivíduos com base em sua atividade, livre e significativa participação nesse processo, orientada pela justa distribuição de benefícios dele resultantes (PIOVESAN, 2012b, p. 104). ${ }^{7}$

Quanto ao direito à participação, como componente da justiça social, destaca Amartya Sen (2000) que a plena realização dos direitos humanos só poderá ser conquistada por meio do exercício efetivo dos direitos políticos, com a real participação de indivíduos e grupos na consecução, exercício e monitoramento de políticas de desenvolvimento, pois, segundo o autor, "political liberties and democratic rights are among the constituent components of development [...]. The protective power of political liberty reveals that no famine has ever taken place in the history of the world in a functioning democracy". ${ }^{8}$

Já no que toca aos programas e políticas nacionais de cooperação internacional, o direito ao desenvolvimento vai demandar mudança ética quanto à distribuição de riquezas e ajuda humanitária aos mais pobres, pois, segundo Mohammed Bedjaoui:

Na realidade, a dimensão internacional do direito ao desenvolvimento é nada mais que o direito a uma repartição equitativa concernente ao bem-estar social e econômico mundial. Reflete uma demanda crucial de nosso tempo, na medida em que os quatro quintos da população mundial não mais aceitam o fato de um quinto da população mundial continuar a construir sua riqueza com base em sua pobreza (BEDJAOUI, 1991, p. 1.182).

7 Reconhece o artigo $2^{\circ}$ da Declaração que: "A pessoa humana é o sujeito central do desenvolvimento e deve ser ativa participante e beneficiária do direito ao desenvolvimento" (BRASIL, 1992a).

8 “As liberdades políticas e os direitos democráticos estão entre os componentes constitutivos do desenvolvimento [...]. O poder protetor da liberdade política revela que nunca houve fome na história do mundo em uma democracia funcional” (Tradução livre dos autores). 
O direito ao desenvolvimento deve ser compreendido, dessa forma, como processo de expansão das liberdades reais, do livre exercício das potencialidades humanas e da busca pela concretização dos direitos fundamentais do homem.

A forma de conscientizar e, de certa forma, controlar e fomentar o avanço dos Estados quanto à repartição igualitária das riquezas - trazendo, se necessário, o maior ônus a quem mais detém condições - é por intermédio de pautas internacionais e sistemas de controle em nível de organismos estrangeiros.

Para tanto, o direito ao desenvolvimento vai necessitar que seja rompida a visão tradicional quanto aos sistemas de verificação e de sanção internacionais, impondo aos Estados o reconhecimento do controle e sancionamento das comissões internacionais, até mesmo para vincular e direcionar as ações dos Estados no sentido de realizar o pleno desenvolvimento de seus nacionais, o que, para Flávia Piovesan:

Em sua complexidade, ao compreender tanto uma dimensão nacional como uma dimensão internacional, o direito ao desenvolvimento tem como violador não apenas o Estado e como vítima não apenas o indivíduo, mas comunidades e grupos. Vale dizer, o direito ao desenvolvimento invoca um padrão de conflituosidade diverso do padrão clássico e tradicional que inspira o sistema de proteção internacional dos direitos humanos (2012b, p. 111).

A jurisprudência da Corte Interamericana dos Direitos Humanos enfatiza a relativização da soberania estatal, ante as obrigações assumidas por meio dos tratados internacionais de proteção aos direitos humanos, quando afirma a possibilidade de os próprios Estados serem julgados perante as Cortes Internacionais no caso de violações de ditas obrigações previstas nos textos internacionais: 
La corte debe enfatizar, sin embargo, que los tratados modernos sobre derechos humanos, en general, y, en particular, la Convención americana, no son tratados multilaterales de tipo tradicional, concluidos en función de un intercambio recíproco de derechos, para el beneficio mutuo de los Estados contratantes. Al aprobar estos tratados sobre derechos humanos, los Estados se someten a un orden legal dentro del cual ellos, por el bien común, asumen varias obligaciones, no en relación con otros Estados, sino hacia los individuos bajo su jurisdición. El carácter especial de estos tratados ha sido reconocido, entro otros, por la Comisión Europea de Derechos Humanos cuando declaró que las obligaciones asumidas por las Altas Partes Contratantes en La Convención (Europea) son esenciamente de carácter objetivo, diseñadas para proteger los derechos fundamentales de los seres humanos de violaciones de parte de Las Altas Partes Contratantes ("Austria vs. Italy", Aplication n. 788/60, European Yearbook of Humans Rights, (1961), vol. 4, p. 140) (Opinión Consultiva OC - 2/82 del 24 de septiembre de 1982. El efecto de las reservas sobre la entrada en vigencia de la Convención Americana sobre Derechos Humanos (arts. 74 y 75) (AYALA, 2001, p. 15).

A existência de mecanismos de pressão internacional, por si só, não resolve a questão da obrigação estatal diante do direito ao desenvolvimento, se não existir, na ordem interna, o compromisso da efetivação dos direitos humanos (e voltados diretamente a essa pauta assumida pelo Estado perante organizações internacionais).

Cançado Trindade reforça a importância da instituição efetiva do direito ao desenvolvimento ao expor que hoje é alarmante o número de pessoas que vivem em condições de extrema vulnerabilidade e pobreza, em decorrência do empobrecimento geral (CANÇADO TRINDADE, 1999, p. 264). Nesse contexto:

A erradicação da pobreza permanece como desafio considerável: a educação e os conhecimentos - a capacitação das pessoas - revestem-se de importância capital para buscar e alcançar o desenvolvimento humano sustentável. Com o atual agravamento do fenômeno trágico 
do empobrecimento de vastos setores da população, as atenções hão de se concentrar na situação dos amplos segmentos da população injustamente excluídos dos benefícios dos chamados "crescimento" e “modernização" (1999, p. 266).

Nesse mundo chamado "globalizado", se por um lado fomenta-se a abertura de capitais a todos os países do globo, por outro fecham-se as fronteiras de circulação livre de pessoas. Concentram-se as riquezas com pouquíssimas pessoas a expensas da tragédia de milhares. Essa nova "tragédia contemporânea" poderia ser perfeitamente evitada se houvesse a primazia da solidariedade humana, e o abandono do egoísmo individual que permeia as sociedades pós-modernas (CANÇADO TRINDADE, 1999, p. 266-267).

Para a promoção do desenvolvimento é necessário que os Estados deem atenção urgente e prioritária à efetivação dos direitos civis, políticos, econômicos, sociais e culturais, pois o reconhecimento do direito ao desenvolvimento como um direito humano pelas Nações Unidas (sendo esta a organização internacional mais importante) só veio reforçar o compromisso da ordem interna em realizar e promover os aludidos direitos (CANÇADO TRINDADE, 1999, p. 280).

Ressalta-se que o direito ao desenvolvimento teve o propósito de fortalecer, e não restringir os direitos humanos preexistentes. A negação ao exercício do direito ao desenvolvimento traz consequências no próprio gozo dos direitos civis e políticos, assim como os econômicos, culturais e sociais.

O Estado, mais especificamente o Brasil (pelo corte geográfico que se fez neste ensaio), não pode deixar ao arbítrio do livre-mercado a responsabilidade da consecução dos objetivos sociais do desenvolvimento humano, sob pena de, não o fazendo, sejam ressuscitados regimes autoritários e violadores dos direitos da pessoa. 


\section{DIREITO INTERNACIONAL DOS DIREITOS HUMANOS E A APLICABILIDADE DO DIREITO AO DESENVOLVIMENTO HUMANO NO DIREITO BRASILEIRO}

Chegou-se ao momento de se acabar com o individualismo. $\mathrm{O}$ individualismo extremado quase levou à ruína da sociedade, quando as pautas autoritárias e funcionalistas (que ocorreram durante a Segunda Guerra Mundial) transgrediram os direitos humanos, cujos efeitos ainda são sentidos até o presente momento.

Fome, miséria, ausência de educação e saúde, moradia rudimentar, marginalização e abandono infantil são algumas das heranças do egocentrismo liberal e do positivismo jurídico, que ocorreram no século 19 e meados do século 20.

O século 20 mal tinha chegado a sua metade e a sociedade rogava por um sistema de direitos que representasse o resgate dos valores voltados à pessoa, bem como a efetivação de sua dignidade. $O$ resultado desse consenso dos países do Ocidente (em sua maioria) foi a internacionalização do sistema de direitos humanos.

Dessa maneira, o final da Segunda Guerra Mundial significou o início do processo de internacionalização dos direitos humanos, o que impulsionou a criação de órgãos de monitoramento internacional, bem como a elaboração de tratados de proteção dos direitos humanos. Com o fim da guerra fria ocorreu a segunda revolução no processo de internacionalização dos direitos humanos, consolidando a necessidade de sua reafirmação como tema de proteção global (PIOVESAN, 2012a, p. 364).

A atual concepção do Direito Internacional dos direitos humanos, todavia, começou a ser construída a partir da chamada "Paz de Westfália", que colocou fim à Guerra dos Trinta Anos, mas os precedentes mais pontuais e que irradiaram efeitos em âmbito global, na maioria dos países oci- 
dentais, foi a consolidação de um sistema internacional de direitos representados por três paradigmas principais: primeiro, o Direito Humanitário; segundo, a Liga das Nações e terceiro, a Organização Internacional do Trabalho (LEWANDOWSKI, 1984, p. 76-84).

Por Direito Humanitário tem-se a definição de Christophe Swinarski como sendo a reunião de normas internacionais, convencionadas ou extraídas do Direito costumeiro, especificamente destinadas a disciplinar conflitos armados (sejam estes nacionais ou internacionais) e que limite os Estados a realizarem certas atitudes ou meios empregados, quando da captura de pessoas ou bens de países beligerantes (1988, p. 18).

Dessa forma, o Direito Humanitário foi o primeiro limite internacional aplicado no contexto de um Estado soberano, restringindo, inclusive, sua atuação.

Já a Liga das Nações, como um segundo esforço de relativização do conceito de soberania e a internacionalização dos direitos humanos, funcionou para a promoção e cooperação dos Estados, na busca da paz e seguranças nacionais. A Convenção estabelecia sanções de ordem econômica e militares a serem impostas pela comunidade internacional contra aqueles Estados que violassem suas obrigações, o que representou a relativização do conceito de soberania, pois os Estados passaram, a partir daquele tratado, a incorporar na sua ordem interna a convivência de compromissos e obrigações internacionais no que toca os direitos humanos (PIOVESAN, 2012a, p. 178-179).

A criação da Organização Internacional do Trabalho também contribuiu para a internacionalização dos direitos humanos, no sentido de buscar promover padrões mínimos de boas condições de trabalho e bem-estar do trabalhador (MAZZUOLI, 2013, p. 861). 
A internacionalização dos direitos humanos representou a consagração da tríplice relação existente entre democracia, desenvolvimento e direitos humanos, o que, para Cançado Trindade, inevitavelmente permitirá a manutenção da paz e a promoção do desenvolvimento social (1994, p. 182).

Segundo Patryck de Araújo Ayala, o Direito alinhou-se na busca da efetividade da cidadania e a concretização da justiça social, que “[...] foram inscritas como formulações constitucionais em diversas Cartas da Europa e, sobretudo, na Carta brasileira de 1988, compondo [...] os 'Novos Direitos dos Homens' [...]” (AYALA, 2001, p. 10).

Essa pauta da reconstrução da cidadania pela valorização dos direitos humanos, concebidos a partir do direito a ter direitos, inscreve-se na tendência verificada no tratamento constitucional que tem sido dado às garantias asseguradas no corpo de instrumentos internacionais, que foram ratificados pelos Estados, quando do estabelecimento de regras que privilegiam a proteção dos direitos humanos, ante o status constitucional que a receberam (AYALA, 2001, p. 10).

Como, afinal, atingir o desenvolvimento humano ou a instituição da justiça social, com a realização de melhores condições de vida a quem é menos favorecido? A resposta vem do exercício do valor (ou princípio) da solidariedade.

Pedro Buck Avelino define solidariedade como:

Atuar humano, de origem no sentimento de semelhança, cuja finalidade objetiva é possibilitar a vida em sociedade, mediante respeito aos terceiros, tratando-os como se familiares o fossem; e cuja finalidade subjetiva é se auto-realizar, por meio da ajuda ao próximo (2005, p. 250).

A Constituição Federal estabelece, como objetivos da República Federativa do Brasil, no seu artigo 3. ${ }^{\circ}$, I, a construção de "uma sociedade livre, justa e solidária”. Ainda, há uma outra finalidade a ser estabelecida 
que é a erradicação da pobreza e da marginalização social e a redução das desigualdades sociais e regionais. Como destaca Maria Celina Bodin de Moraes, esses objetivos foram inseridos no título do Texto Constitucional denominado “Dos Princípios Fundamentais” e, gozando dessa condição, possuem a natureza de ser preponderante na ordem interna, impondo a sua plena realização pelos poderes públicos e destinatários da Carta Magna (MORAES, 2006, p. 158).

Assim, é perfeitamente possível afirmar que os poderes públicos estão obrigados a efetivar a concepção de "justiça distributiva”, ou seja, aquela voltada a retirar as desigualdades substanciais, o que determina como meta primordial a solidariedade social, mediante a busca da melhor qualidade de vida e redução dos desequilíbrios regionais.

O princípio da solidariedade possui dois enfoques principais: enquanto analisado sob a perspectiva objetiva, significa a coexistência dos indivíduos, pois não se pode imaginar uma realidade na qual o homem viva sozinho, ou, para Hannah Arendt, "quem habita este planeta não é o Homem, mas os homens. Pluralidade é a lei da terra” (ARENDT, 1999, p. 188). Já sob a perspectiva valorativa, a solidariedade representa a obrigação moral de não fazer aos outros o que não se quer que seja feito a você (MORAES, 2006, p. 160).

A conjugação dessas duas perspectivas da solidariedade fundou a própria base das sociedades modernas, ou seja, a solidariedade foi o que motivou a reunião de indivíduos para a concretização do bem comum:

Aos individualmente considerados vieram, porém, a se substituir os grupos organizados, as comunidades intermediárias, as coletividades que têm, cada uma, o seu próprio interesse. Tudo passa a se referir à sociedade, uma referência que não tem outra referência a não ser ela própria e que mantém a sua coesão através de uma rede invisível de mútua interdependência. Começava a tomar forma uma igualdade 
de direitos fundada em valores sociais, fecundada pela solidariedade social, que servirá de base à igualdade substancial e à justiça social (MORAES, 2006, p. 161).

A solidariedade, desse modo, representa a consagração dos chamados "Direitos de Terceira Geração" voltados ao "gênero humano" e a própria obrigação dos Estados em cuidar de manter a existência digna das pessoas, bem como proporcionar a realização do bem comum, por meio do desenvolvimento das pessoas.

Segundo Cançado Trindade (1999, p. 281), a cristalização dos direitos de terceira geração, mormente ao estabelecer o direito ao desenvolvimento com status de direito humano, foi ocasionado por meio das mudanças internacionais históricas ocorridas na sociedade, por exemplo, a descolonização, os anseios de imperativos sociais, a descoberta e desenvolvimento de armamentos com capacidade de destruição em massa, o crescimento populacional versus a sustentabilidade ambiental, padrões de consumo modificados, enfim, o direito ao desenvolvimento reforça os direitos preexistentes e estatui os requisitos para a concretização material ao desenvolvimento humano:

O direito ao desenvolvimento teve propósito de fortalecer, jamais restringir, os direitos pré-existentes. Assim ocorre em razão da natureza complementar de todos os direitos humanos. Todos os aspectos do direito ao desenvolvimento, por sua vez, são do mesmo modo interdependentes e hão de ser levados em conta como um todo. Assim, uma denegação do direito ao desenvolvimento há de acarretar consequências adversas para o exercício dos direitos civis e políticos, assim como dos direitos econômicos, sociais e culturais. O reconhecimento e a cristalização do direito ao desenvolvimento só puderam ter ocorrido à luz da unidade e de concepção e indivisibilidade dos direitos humanos (CANÇADO TRINDADE, 1999, p. 281). 
Esses direitos humanos de terceira geração possuem vínculos inquestionáveis com a paz, segurança e estabilidade sociais, as quais serão efetivadas com a superação da pobreza e exclusão social, com o fortalecimento do bem-estar dos povos, não sendo o desenvolvimento econômico, por exemplo, um fim em si mesmo, mas sim um meio a serviço do Estado para atingir a chamada justiça social (CANÇADO TRINDADE, 1999, p. 282).

A solidariedade vai demandar, outrossim, certa ruptura da soberania dos Estados, uma vez que se faz necessário o cumprimento dos instrumentos internacionais de proteção dos direitos humanos na ordem interna, o que limitará a possibilidade de os Estados formularem reservas aos tratados que tenham por conteúdo a proteção aos direitos humanos (AYALA, 2001, p. 14-15).

Sem dúvida o princípio da solidariedade, por meio da reunião de esforços da sociedade, para atingir o bem comum, é objetivo a ser seguido pelo Brasil, e essa conclusão é extraída das seguintes premissas:

1) $\mathrm{O}$ artigo 56 da Carta da ONU, no qual todos os membros da aludida Organização se comprometem a agir em cooperação com a Carta, em conjunto ou separadamente, para a realização dos propósitos enumerados no artigo 55, que são, entre outros, estabelecer "níveis mais altos de vida, trabalho efetivo e condições de progresso e desenvolvimento econômico e social e a solução dos problemas internacionais econômicos, sociais, sanitários e conexos”. Isso faz gerar o que se denomina de "dever de cooperação internacional para o desenvolvimento" (BRASIL, 1945);

2) O artigo 28 da Declaração Universal dos Direitos Humanos, o qual preceitua que "toda pessoa tem direito a uma ordem social e internacional em que os direitos e liberdades estabelecidos na presente Declaração possam ser plenamente realizados”, bem na linha do conceito que se 
adota quando do significado do termo desenvolvimento, qual seja, o de ser um instrumento de realização de liberdades reais e instrumentais (SILVA, 2013, p. 209).

3) $\mathrm{O}$ artigo 26 da Convenção Americana, o qual traz expressamente a obrigação dos Estados de colocarem em prática o "desenvolvimento progressivo", definido como o compromisso de os Estados adotarem medidas "a fim de conseguir progressivamente a plena efetividade dos direitos que decorrem das normas econômicas, sociais e sobre educação, ciência e cultura, constantes da Carta da Organização dos Estados Americanos [...]” (BRASIL, 1992c);

4) O artigo $3^{\circ}$, inciso II, da Constituição Federal de 1988, no qual é trazido como objetivo da República Federativa brasileira a realização do desenvolvimento nacional, ou seja, o compromisso de proporcionar as condições necessárias (e condizentes) aos indivíduos de plenamente exercerem as liberdades individuais, os direitos políticos, e serem senhores da própria vontade, quando do exercício de suas potencialidades humanas (BRASIL, 1988).

No prisma constitucional, os exemplos da instauração do princípio solidariedade, como consagração do direito ao desenvolvimento humano, podem ser retirados por meio de algumas políticas públicas, por exemplo, quanto aos "princípios da seguridade social”, artigo 194 da Constituição Federal, ${ }^{9}$ que possibilitam o resguardo financeiro aos não economicamente ativos, quando não mais possível o exercício laboral.

\footnotetext{
9 Assegura o artigo 194 da CF/88 o seguinte: "A seguridade social compreende um conjunto integrado de ações de iniciativa dos Poderes Públicos e da sociedade, destinadas a assegurar os direitos relativos à saúde, à previdência e à assistência social. Parágrafo único. Compete ao Poder Público, nos termos da lei, organizar a seguridade social, com base nos seguintes objetivos: I - universalidade da cobertura e do atendimento; II - uniformidade e equivalência dos benefícios e serviços às populações urbanas e rurais; III - seletividade e distributividade na prestação dos benefícios e serviços; IV - irredutibilidade do valor dos benefícios; V - eqüidade na forma de participação no custeio; VI - diversidade da base de
} 
Um dos princípios da seguridade social que garante o desenvolvimento e manutenção da condição digna da pessoa é a da "universalidade subjetiva”, ou seja, independentemente de contribuição, ou da condição econômica, toda a pessoa pode receber do Estado o benefício que lhe garanta a subsistência (SILVA, 2007, p. 761).

Também pode ser destacado, como complemento do projeto solidarista da Constituição Federal de 1988 voltado ao desenvolvimento humano, a Emenda Constitucional n.31, que cria o "Fundo de Combate e Erradicação da Pobreza” (Fundo este prorrogado por tempo indeterminado por meio da Emenda Constitucional n. 67), com a finalidade de:

Art. 79, da ADCT: [...] viabilizar a todos os brasileiros acesso a níveis dignos de subsistência, cujos recursos serão utilizados em ações suplementares de nutrição, habitação, educação, saúde, reforço da renda familiar e outros programas de relevante interesse social voltados para melhoria da qualidade de vida (BRASIL, 1988).

Assim, a internacionalização dos direitos humanos representa ao Estado brasileiro salto qualitativo em relação à proteção dos direitos humanos, no sentido de que trouxe a obrigação do Brasil de realizar efetivamente, mediante o princípio da solidariedade, o direito ao desenvolvimento humano, no emprego de algumas políticas públicas, corolário do direito de Terceira Geração, representando, ainda, objetivo a ser seguido pela República brasileira, base fundante da ordem democrática.

financiamento; VII - caráter democrático e descentralizado da administração, mediante gestão quadripartite, com participação dos trabalhadores, dos empregadores, dos aposentados e do Governo nos órgãos colegiados” (BRASIL, 1988). 


\section{CONCLUSÕES}

Após o fim da Segunda Guerra Mundial convencionou-se a necessidade de os países criarem instrumentos internacionais de proteção dos direitos humanos, principalmente para que estes pudessem proporcionar as condições necessárias ao desenvolvimento das pessoas, o bem-estar coletivo internacional, instituindo a solidariedade dos povos, como corolário da paz mundial.

Os valores voltados às liberdades públicas (consagradas na primeira geração de direitos), bem como os direitos prestacionais (consagrados na segunda geração de direitos) - cujo rol era livremente estabelecido na ordem interna de cada país - são somados aos tratados e normas internacionais voltados à proteção da pessoa humana, inaugurando-se os denominados direitos de Terceira Geração.

Os direitos de Terceira Geração possuem vínculos inquestionáveis com a paz, segurança e estabilidade sociais, com a justiça social e, em consequência, o desenvolvimento humano, pautas estas que só serão efetivadas por meio da superação da pobreza e exclusão social, e que demandará esforços comuns (solidariedade dos povos) no sentido de superarem entraves normativos (legislação interna), por meio de um sistema internacional de proteção dos direitos humanos (mesmo que isso represente certa quebra da própria soberania estatal).

A instituição do sistema internacional dos direitos humanos deu-se por meio da convergência de um sistema global (integrado pelos instrumentos das Nações Unidas, como a Declaração Universal de Direitos Humanos, o Pacto Internacional dos Direitos Civis e Políticos, o Pacto Internacional dos Direitos Econômicos, Sociais e Culturais), com os instrumentos dos sistemas regionais de proteção, com destaque para o sistema interamericano, no qual o Brasil é signatário. 
A Convenção Americana de Direitos Humanos (sistema interamericano), como sistema regional de proteção da dignidade da pessoa, reproduziu os principais instrumentos protetivos do Pacto dos Direitos Civis e Políticos (sistema global), mas também inseriu, no bojo do Tratado, a obrigação de os Estados signatários promoverem os direitos voltados à dignidade, principalmente aqueles voltados ao desenvolvimento humano, conforme previsão do artigo 26 da Convenção.

Embora o Brasil não tenha ratificado o ato internacional da Declaração Sobre o Direito ao Desenvolvimento da ONU de 1986, este fato não retira a obrigação jurídica do Estado brasileiro de promover o desenvolvimento da pessoa humana no território nacional, sobretudo quando o país optou por fazer parte dos sistemas protetivos de internacionalização da proteção dos direitos humanos.

Essa obrigação jurídica também é retirada do artigo $3^{\circ}$, inciso II da Constituição Federal de 1988, que traz como objetivo fundamental da República Federativa do Brasil a garantia ao desenvolvimento nacional (BRASIL, 1988).

O direito ao desenvolvimento humano é pauta prioritária do Estado brasileiro, uma vez que se faz necessário o cumprimento dos instrumentos internacionais de proteção dos direitos humanos na ordem interna, ou seja, o Brasil pela leitura sistemática dos tratados internacionais de direitos humanos, dos quais é signatário, bem como pela própria construção dos valores da Constituição Federal, sobretudo dos valores da dignidade humana, permite afirmar que o desenvolvimento humano é compromisso obrigatório ao Estado brasileiro, por meio de políticas públicas.

No Brasil, algumas políticas públicas para estabelecer o direito ao desenvolvimento humano (e trazer o mínimo de bem-estar social) já são realizadas, tais como o sistema da seguridade social (artigo $194 \mathrm{da} \mathrm{CF} / 88$ ), que possibilita o resguardo financeiro aos não economicamente ativos, 
quando não mais possível o exercício laboral, garantindo-se, inclusive, a renda de um salário àqueles que nunca contribuíram para a Previdência Social, desde que provada a situação de miserabilidade financeira.

Outro exemplo destacado é a Emenda Constitucional 31, que criou o "Fundo de Combate e Erradicação da Pobreza", que visa a dar mínimas condições dignas aos brasileiros em relação à alimentação, habitação, educação, saúde, etc.

A conclusão a que se chega é que, apesar de existirem algumas políticas públicas desenvolvidas para atingir a chamada parcela carente, o princípio da solidariedade, por meio do desenvolvimento, tem muito a evoluir, posto que ainda existem muitos outros compromissos assumidos pelo Estado brasileiro no contexto de tratados internacionais, que ainda merecem ter planos de ação próprios, como é o caso, por exemplo, da erradicação da fome.

O que também se conclui é que o princípio do desenvolvimento humano detém natureza vinculativa ao Brasil, não sendo possível que o Estado retroceda, sob suposta alegação de soberania e aplicação da legislação local, quanto aos direitos e políticas públicas já desenvolvidas, pois a internacionalização dos direitos humanos impõe o exercício de agendas políticas voltadas a proporcionar melhores condições de vida à população, cuidando de realizar o efetivo progresso do povo brasileiro.

\section{REFERÊNCIAS}

ABREGÚ, Martín. Direitos humanos para todos: da luta contra o autoritarismo à construção de uma democracia inclusiva - um olhar a partir da região Andina e do Cone Sul. Sur. Revista Internacional de Direitos Humanos, São Paulo, ano 5, p. 6-41, jun. 2008.

ARENDT, Hannah. A condição humana. 9. ed. São Paulo: Forense Universitária, 1999. 
AVELINO, Pedro Buck. Princípios da solidariedade: imbricações históricas e sua inserção na constituição de 1988. Revista de Direito Constitucional e Internacional, São Paulo: RT, n. 53, 250 p., out./dez. 2005.

AYALA, Patryck de Araújo. O Direito Internacional dos Direitos Humanos e o direito a ter direitos sob uma perspectiva de gênero. Revista de Direito Constitucional e Internacional: Cadernos de Direito Constitucional e Ciência Política, São Paulo, v. 36, n. 9, p. 7-34, jul./set. 2001. Trimestral.

BEDJAOUI, Mohammed. International Law: Achievements and Prospects. Paris: Unesco, 1991.

BRASIL. Constituição Federal de 5 de outubro de 1988. Constituição da República Federativa do Brasil de 1988. Disponível em: <http://www.planalto.gov. br/ccivil_03/constituicao/constituicaocompilado.htm>. Acesso em: 24 nov. 2016.

. Decreto $\mathrm{n}^{\mathrm{o}}$ 19.841, de 22 de outubro de 1945. Promulga a Carta das Nações Unidas, da qual faz parte integrante o anexo Estatuto da Corte Internacional de Justiça, assinada em São Francisco, a 26 de junho de 1945, por ocasião da Conferência de Organização Internacional das Nações Unidas. Decreto. Brasília, DF, 22 out. 1945. Disponível em: <http://www.planalto.gov. br/ccivil_03/decreto/1930-1949/d19841.htm>. Acesso em: 23 fev. 2017.

. Decreto $\mathrm{n}^{\circ}$ 591, de 6 de julho de 1992. Atos Internacionais. Pacto Internacional sobre Direitos Econômicos, Sociais e Culturais. Promulgação. Decreto. Brasília, DF, 7 jul. 1992a. Disponível em: <http://www.planalto.gov. br/ccivil_03/decreto/1990-1994/d0591.htm>. Acesso em: 23 fev. 1992.

. Decreto $\mathrm{n}^{\mathrm{0}}$ 592, de 6 de julho de 1992. Atos Internacionais. Pacto Internacional sobre Direitos Civis e Políticos. Promulgação. Decreto. Brasília, DF, 7 jul. 1992b. Disponível em: <http://www.planalto.gov.br/ccivil_03/ decreto/1990-1994/d0592.htm>. Acesso em: 23 fev. 1992. 
BRASIL. Decreto no ${ }^{\circ}$ 78, de 6 de novembro de 1992. Promulga a Convenção Americana sobre Direitos Humanos (Pacto de São José da Costa Rica), de 22 de novembro de 1969. Convenção Americana Sobre Direitos Humanos. Brasília, DF, 6 nov. 1992c. Disponível em: <http://www.planalto.gov.br/ccivil_03/ decreto/D0678.htm>. Acesso em: 13 fev. 2017.

BRITO, Bernardo de Azevedo. Os Direitos Humanos e a identidade cultural dos povos. In: CICLO DE PALESTRAS DO PROGRAMA ESPECIAL DE TREINAMENTO (PET), 1, 1998, Florianópolis. Palestra. Florianópolis: Faculdade de Direito da UFSC, 1998. Disponível em: <http://www.dhnet.org.br/direitos/ textos/textos_dh/dh_identidade.html>. Acesso em: 13 fev. 2017.

BUERGENTHAL, Thomas; NORRIS, Robert. Human rights: the inter-American system. Nova York: Oceana Publications, 1982.

CANÇADO TRINDADE, Antônio Augusto. A proteção internacional dos direitos humanos no limiar do novo século e as perspectivas brasileiras. In: Temas de política externa brasileira, II. Brasília: Ministério das Relações Exteriores, 1994 , v. I.

Tratado de Direito Internacional dos Direitos Humanos. Volume II. Porto Alegre: Sergio Antonio Fabris Editor, 1999. Vol. II.

CASSIN, René. El problema de la realización de los derechos humanos en la sociedad universal. In: Veinte años de evolución de los derechos humanos. México: Instituto de Investigaciones Jurídicas, 1974.

CHAPMAN, Audrey. A new approach to monitoring the International Covenant on Economic, Social and Cultural Rights. International Commission of Jurists, The Review., n. 55, dec. 1995.

CLÉVE, Clémerson Merlin. A Teoria Constitucional e o Direito Alternativo: para uma dogmática constitucional emancipatória. In: Carlos Henrique de Carvalho Filho. (Org.). Uma vida dedicada ao Direito: homenagem a Carlos Henrique de Carvalho. O editor dos juristas. São Paulo: Editora Revista dos Tribunais, 1995. p. 34-53.

COMPARATO, Fábio Konder. A afirmação histórica dos direitos humanos. São Paulo: Saraiva, 1999. 
FAZOLI, Carlos Eduardo de Freitas; SILVA, Fernando Henrique Rugno da. A tutela interdital: um instrumento para a efetivação dos direitos fundamentais. Revista Direitos Sociais e Políticas Públicas - Unifafibe, v. 2, n. 2, 2014.

HESPANHA, Antônio Manuel. Panorama histórico da cultura jurídica européia . Lisboa: Publicações Europa-América, 1997.

HEYNS, Cristof; VILJOEN, Frans. An overview of human rights protection in Africa. South African Journal on Human Rights, Johannesburg, p. 0-423, jan. 1999.

LAFER, Celso. Comércio, desarmamento, direitos humanos: reflexões sobre uma experiência diplomática. São Paulo: Paz e Terra, 1999.

LEWANDOWSKI, Enrique Ricardo. Proteção dos direitos humanos na ordem interna e internacional. Rio de Janeiro: Forense, 1984.

MAZZUOLI, Valerio de Oliveira. Curso de direito internacional público. 7. ed. rev., atual. e ampl. São Paulo: Editora Revista dos Tribunais, 2013.

MORAES, Maria Celina Bodin de. O princípio da solidariedade. In: PEIXINHO, Manoel Messias; GUERRA, Isabella Franco; NASCIMENTO FILHO, Firly (Org.). Os princípios da Constituição de 1998. Rio de Janeiro: Lumen Juris, 2006. p. 157-176.

OLIVEIRA, Leandro Dias de. A geopolítica do desenvolvimento sustentável: um estudo sobre a Conferência do Rio de Janeiro (Rio-92). 2011. 267 f. Tese (Doutorado) - Universidade Estadual de Campinas - Unicamp, Curso de Geografia, Instituto de Geociências, Campinas, 2011. Disponível em: <http://pct.capes. gov.br/teses/2011/33003017080P0/TES.PDF>. Acesso em: 27 maio 2017.

ORGANIZAÇÃO DAS NAÇÕES UNIDAS (ONU). Comissão Mundial Sobre Meio Ambiente e Desenvolvimento. Nosso Futuro Comum. Rio de Janeiro: Ed. FGV, 1988.

PIOVESAN, Flávia. Direitos humanos e o direito constitucional internacional. 13. ed., rev. e atual. São Paulo: Saraiva, 2012a. . Temas de direitos humanos. 5. ed. São Paulo: Saraiva, 2012b. 
ROSAS, Allan. The right to development. In: EIDE, Asbjorn; KRAUSE, Catarina; ROSAS, Allan. Economic, social and cultural rights. Dordrecht; Boston; London: Martinus Nijhoff Publishers, 1995. p. 254-255.

SARMENTO, Daniel. Direitos Fundamentais e Relações Privadas. São Paulo: Editora Lumen Júris, 2004.

SEN, Amartya Kumar. Desenvolvimento como liberdade. Trad. Laura Teixeira Motta. São Paulo: Companhia das Letras, 2000.

SHELTON, Dinah L. An Introduction to the History of International Human Rights Law (August 2007). In: GWU Legal Studies Research Paper, n. 346, aug. 2007. Disponível em: <https://ssrn.com/abstract=1010489 or http://dx.doi. org/10.2139/ssrn.1010489>.

SILVA, Adriana Lopes da (Org.). Direitos Humanos. 4. ed. Brasília: Senado Federal; Coordenação de Edições Técnicas, 2013. Disponível em: <https:// www2.senado.leg.br/bdsf/bitstream/handle/id/508144/000992124. pdf?sequence=1>. Acesso em: 23 fev. 2017.

SILVA, José Afonso da. Comentário contextual à Constituição. 5. ed. São Paulo: Malheiros Editores, 2007.

SIQUEIRA, Dirceu Pereira; FERRARI, Caroline Clariano. O direito à informação como direito fundamental ao Estado democrático. Revista Direitos Sociais e Políticas Públicas - Unifafibe, v. 4, n. 2, 2016.

A dimensão cultural do direito fundamental à alimentação. Birigui: Boreal, 2013.

. Tutela coletiva do direito à saúde. Franca: Lemos e Cruz, 2010.

SOUZA, Nali de Jesus. Desenvolvimento econômico. São Paulo: Atlas, 1995.

STEINER, Henry J. International human rights in context - law, politics and morals. 2. ed. Oxford: Oxford University Press, 2000.

SWINARSKI, Christophe. Introdução ao direito internacional humanitário. Brasília: Escopo, 1988.

ZOLA, Émile. Germinal. São Paulo: Martin Claret, 2006. V. 41. (Col. A obra-prima de cada autor - série ouro). 